УДК 633.812:663.479.1

DOI 10.29141/2500-1922-2020-5-3-4

\title{
Применение экстракта
} Agrimonia eupatoria $L$.

\section{для производства кваса}

Ю.Ю. Миллер ${ }^{1}$, О.В. Голуб ${ }^{1 *}$, К.В. Захарова ${ }^{1}$

${ }^{1}$ Сибирский университет потребительской кооперации, г. Новосибирск, Российская Федерация, *e-mail: expertis@sibupk.nsk.su

Ключевые слова:
Agrimonia
еuраtогіа L.;
квас;
экстракm
растительного
сырья;
полифенольные
вещества;
аскорбиновая
кислота;
качественные
характеристики

\begin{abstract}
Реферат
Статья посвящена исследованию возможности использования травы репешок обыкновенный (Agrimonia eupatoria L.) при изготовлении кваса, поскольку растение обладает повышенным содержанием вкусоароматических и биологически активных веществ (флавоноидов, дубильных веществ, арбутина и т. д.). Работа выполнялась с помощью стандартных, принятых в пивобезалкогольной отрасти методов испытаний, а также способов обработки полученных результатов. Для выработки кваса с наилучшими качественными характеристиками следует использовать экстракт Agrimonia eupatoria L. Установлено, что с целью получения данного экстракта с максимальным количеством вкусоароматических и биологически активных веществ (полифенольных веществ, аскорбиновой кислоты) мацерацию измельченной до 3-5 мм травы следует проводить, используя в качестве растворителя очищенную воду в соотношении 1:10 при температуре $40 \pm 3{ }^{\circ} \mathrm{C}$ в течение 5-6 ч. Экстракт Agrimonia eupatoria L. представляет собой непрозрачную жидкость коричневого цвета с зеленоватым оттенком, слабо выраженными сладко-абрикосовым ароматом и вкусом; массовая доля сухих веществ - 3,0 $\pm 0,1 \%$; кислотность $-2,5 \pm 0,2$ к. ед.; содержание полифенольных веществ - не менее 13,5 мг / $100 \mathrm{~cm}^{3}$; содержание аскорбино-

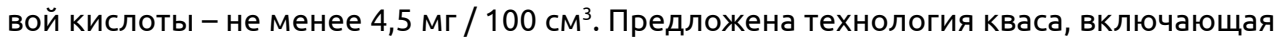
приготовление квасного сусла и экстракта Agrimonia eupatoria L. по отдельности, их купажирование, сбраживание, охлаждение, осветление и розлив. На основании органолептических и физико-химических показателей, полученных при проведении исследований, рекомендовано оптимальное соотношение квасного сусла и экстракта Agrimonia eupatoria L. 90:10-80:20. Установлены регламентируемые показатели качества нового кваса: внешний вид - прозрачная пенящаяся жидкость с опалесценцией, без посторонних включений; цвет - коричневый с зеленоватыми тонами; аромат и вкус - освежающие, кисло-сладкие, хлебные, с легкими тонами экстракта Agrimonia eupatoria L. Использование водного экстракта из травы Agrimonia eupatoria L. в производстве кваса позволяет получить продукцию с оригинальными органолептическими характеристиками.
\end{abstract}

Для цитирования: Миллер Ю.Ю., Голуб О.В., Захарова К.В. Применение экстракта Agrimonia eupatoria L. для производства кваса // Индустрия питания/Food Industry. 2020. T. 5, № 3. С. 35-43. DOI: 10.29141/2500-1922-2020-5-3-4

\section{Application of the Agrimonia eupatoria $L$. Extract for the Kvases Production}

\section{Yuliya Yu. Miller ${ }^{1}$, Olga V. Golub ${ }^{1 *}$, Karina V. Zakharova}

'Siberian University of Consumer Cooperation, Novosibirsk, Russian Federation, *e-mail: expertis@sibupk.nsk.su

Keywords:

Agrimonia eupatoria L.; kvass;

\section{Abstract}

The article concerns the research of the herb Common Agrimony (Agrimonia eupatoria L.) use in the kvass manufacture, because the plant has a high content of flavoring and bio- 
vegetable raw material extract;

polyphenolic

substances;

ascorbic acid;

qualitative

characteristics logically active substances (flavonoids, tannins, arbutin, etc.). Researchers used standard, adopted in the brewing and soft drinks industry test methods and methods of processing obtained results. To produce kvass with the best quality characteristics, a man has to use Agrimonia eupatoria L. extract. In order to obtain this extract with the maximum amount of flavoring and biologically active substances (polyphenolic substances, ascorbic acid) a man must macerate 3-5 mm cut grass using purified water as a solvent in a ratio of 1:10 at a temperature of $40 \pm 3{ }^{\circ} \mathrm{C}$ for 5-6 hours. Agrimonia eupatoria L. extract is an opaque brown liquid with a weak greenish tint, weakly expressed sweet-apricot aroma and taste; the mass fraction of dry substances is $3.0 \pm 0.1 \%$; acidity $-2.5 \pm 0.2$ units; the content of polyphenolic substances is not less than $13.5 \mathrm{mg} / 100 \mathrm{~cm} 3$; the content of ascorbic acid - not less than $4.5 \mathrm{mg} / 100 \mathrm{~cm}^{3}$. The authors developed kvass technology, including the preparation of kvass wort and Agrimonia eupatoria L. extract separately, its blending, fermentation, cooling, clarification and bottling. Based on the organoleptic and physical and chemical parameters obtained during the study, the researchers recommended the optimal ratio of kvass wort and Agrimonia eupatoria L.: 90:10 - 80:20. They developed regulated quality indicators of the new kvass: appearance - a transparent foaming liquid with opalescence, without foreign inclusions; color - brown with greenish tones; aroma and taste - refreshing, sweet and sour, bread, with light tones of Agrimonia eupatoria L. extract. The use of an aqueous extract from the herb Agrimonia eupatoria $L$. in the kvass production enables to get products with original organoleptic characteristics.

For citation: Yuliya Yu. Miller, Olga V. Golub, Karina V. Zakharova. Application of the Agrimonia Eupatoria L. Extract for the Kvases Production. Индустрия питания|Food Industry. 2020. T. 5, No. 3. Pр. 35-43. DOI: 10.29141/2500-1922-2020-5-3-4

Paper submitted: May 17, 2020

Актуальность

Всё большей популярностью среди населения пользуются продукты питания на основе / с использованием натурального растительного сырья, отличающиеся повышенной пищевой ценностью, в том числе за счет наличия физиологически активных веществ. Растительное сырье в пищевую продукцию вводится, в основном, в виде экстрактов, что предопределяет необходимость всестороннего изучения данного технологического приема. Вопросами мацерации растительного сырья для производства продуктов питания занимаются многие ученые $[1 ; 2]$ В настоящее время для мацерации растительного сырья применяются различные способы: водный, спиртовой, ультразвуковой и др. [2; 3]. При выборе способа мацерации учитываются следующие факторы:

- природа растворителя - должен быть безопасным, способным максимально извлекать из сырья требуемые вещества, быть доступным;

- температура мацерации - должна не только ускорять извлечение необходимых веществ, но и способствовать их сохранению;

- степень дисперсии растительного сырья измельчение сырья необходимо для извлечения экстрактивных веществ в растворитель за счет разрыва растительных тканей. Следует отметить, что слишком мелкое измельчение, наблюдаемое вследствие большого разрушения клеточных тканей, вызывает переход в экстракт, В дополнение к необходимым соединениям, нежелательных веществ, в том числе нерастворимых, коллоидов и пр., провоцирующих ухудшение его качественных характеристик (помутнение, дестабилизацию и др.), а крупное измельчение не способствует полному извлечению из сырья требуемых веществ;

- соотношение сырья и растворителя;

- продолжительность технологического приема; и т. д.

Перспективным для производства пищевых продуктов является репешок обыкновенный (Agrimonia eupatoria L.), представляющий собой достаточно высокое (до 1 м) многолетнее травянистое растение с мохнатым стеблем, сероватыми листьями и золотисто-желтыми цветками со специфическим, приятным запахом. В настоящее время растение Agrimonia eupatoria $L$. не включено В Государственную фармакопею Российской Федерации; в его отношении отсутствует нормативная документация, но при этом оно широко применяется при лечении / профилактике многих заболеваний - сердечно-сосудистых, заболеваний мочевого пузыря и почек, пищеварительной системы и печени, для остановки кровотечений, для заживления ран, при кожных и инфекционно-воспалительных заболеваниях при опухолевой активности и пр. $[4 ; 5 ; 6 ; 7]$. 
Использование Agrimonia eupatoria L. обусловлено особенностями химического состава, В первую очередь содержанием комплекса полифенольных соединений, отличающихся Р-витаминной и антиоксидантной активностью, полисахаридов, преимущественно гемицеллюлоз, витаминов группы B, C, K, минеральных веществ и других физиологически активных компонентов $[8 ; 9 ; 10 ; 11 ; 12]$.

Сегодня Agrimonia eupatoria L. не входит в перечень добавок, запрещенных к использованию при изготовлении пищевой продукции согласно TP ТС 029/2012 «Требования безопасности пищевых добавок, ароматизаторов и технологических вспомогательных средств» ${ }^{1}$.

Химический состав Agrimonia eupatoria L. предопределяет широкие перспективы использования его полуфабрикатов в пищевых технологиях (табл. 1). При этом следует отметить, что в настоящее время Agrimonia eupatoria L. не используется для производства безалкогольных напитков.

\footnotetext{
${ }^{1}$ TP ТС 029/2012. Технический регламент Таможенного союза «Требования безопасности пищевых добавок, ароматизаторов и технологических вспомогательных средств». Принят Решением Совета Евразийской экономической комиссии от 20 июля 2012 г. № 58.
}

Цель работы - исследование влияния экстракта травы Agrimonia eupatoria L. на качественные характеристики кваса.

\section{Объекты и методы исследования}

Объекты исследования - квас с экстрактом Agrimonia eupatoria L.; предмет исследования - качественные характеристики экстракта Agrimonia eupatoria L. и кваса с его использованием.

При проведении исследований были использованы трава Agrimonia eupatoria L. и квас сухой хлебный (характеристики представлены в табл. 2), а также сахар ГОСТ 33222-2015 «Сахар белый. Технические условия".

Получение квасного сусла. Сухой ингредиент (квас) смешивали с водой температурой $90-95^{\circ} \mathrm{C}$ в соотношении 1:1,5; смесь настаивалась в течение 30 мин для клейстеризации присутствующего в сухом ингредиенте крахмала, подготовки полисахаридов для последующего осахаривания; добавляли воду температурой $90-95{ }^{\circ} \mathrm{C}$ в количестве, позволяющем обеспечить ее соотношение с сухим ингредиентом 1:10-1:12; смесь настаивалась в течение 70-80 мин до температуры $37^{\circ} \mathrm{C}$ с целью экстрагирования водорастворимых веществ сухого ингредиента гидролиза углеводных и белковых соединений различной молекулярной массы; полученный затор фильтровали.

Таблица 1. Использование полуфабрикатов Agrimonia eupatoria L. при изготовлении пищевой продукции Table 1. Use of Agrimonia eupatoria L. Semi-Finished Products in the Food Manufacture

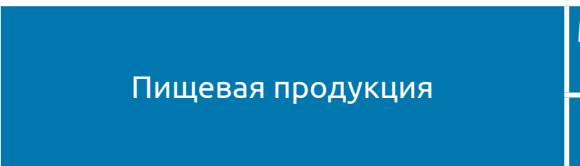

\begin{tabular}{|c|l|l|l|}
\hline $\begin{array}{c}\text { Мелкоизмель- } \\
\text { ченные }\end{array}$ & $\begin{array}{c}\text { Водно-спиртовой } \\
\text { экстракт }\end{array}$ \\
\hline Трава & Корни & Травы & Листьев \\
\hline
\end{tabular}

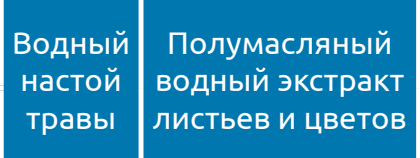

Спиртоводный эКстракт травы

Фиточай

Растительный набор [13]

Композиция ингредиентов для приготовления лечебнопрофилактического бальзама [13]

Бальзам $\mathrm{M}^{\mathrm{\Gamma}}[13]$

Водка [13]

Настойкаम

Колбаса [13]

Биологически активная добавка к пище [13]

\begin{tabular}{|c|c|c|c|c|c|c|}
\hline+ & + & - & - & - & - & - \\
\hline+ & - & - & - & - & - & - \\
\hline- & - & - & - & - & + & - \\
\hline- & - & + & + & - & - & - \\
\hline- & - & + & - & - & - & - \\
\hline- & - & + & - & - & - & - \\
\hline- & - & - & - & - & - & - \\
\hline 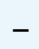 & - & - & - & + & - & - \\
\hline
\end{tabular}

\footnotetext{
Примечания:
}

АЗаявка на патент РФ 2008129526/13. Фиточай: МПК А23F 3/34 / Карманова Е.А., Канцур В.И.; Заявка подана: 21.07.2008, опубликована: 27.01.2010.

БПатент РФ 2700629. Композиция чая травяного (фиточая): МПК A23F 3/00, A23F 3/34 / ФГБОУ ВО «СОУГ им. К.Л. Хетагурова» / Лавриненко Ю.В., Николаев И.А.; Заявка: 2018108287; подана: 06.03.2018, опубликована: 18.09 .2019$.

вПатент РФ 2297237. Докторский бальзам «Здоровья для» / Данилин В.Н.; Заявка: 2004137180/15; подана: 20.12.2004, опубликована: 20.04.2007.

ГПатент РФ 2375434. Композиция ингредиентов для бальзама / ГНУ «НИИСХ КС СО Россельхозакадемии»: Тюпкина Г.И., Шелепов В.Г., Лайшев К.А. и др.; Заявка: 2007138544/13; подана: 16.10.2007, опубликована: 10.12.2009.

дПатент РФ 2323736. Настойка «Сергеевская» / Ивашкин С.Н.; Заявка: 2005108478; подана: 15.03.2005, опубликована: 10.05.2008. 
Таблица 2. Качественные характеристики сырья, входящего в экстракт Agrimonia eupatoria $L$. Table 2. Qualitative Characteristics of Raw Materials Included in the Agrimonia eupatoria L. Extract

Показатель
Внешний вид
Цвет
Запах
Вкус
Массовая доля влаги, \%
Кислотность, к.ед.
Крупность помола, остаток на сите из сетки
проволочной тканной, \%
Массовая доля металломагнитной примеси
(частиц размером не более 0,3 мм в наиболь-
шем линейном измерении) на 1 кг, мг
Посторонние включения; хруст от минераль-
ной примеси; признаки болезней и плесени;
зараженность вредителями хлебных запасов
Массовая доля полифенольных веществ, \%
Массовая доля аскорбиновой кислоты, мг/100г

Квас сухой хлебный

Однородная сыпучая масса

в виде крупки, достаточно однородная по размеру; отсутствуют неплотно слежавшиеся комочки

Светло-коричневый

Ржаного хлеба; без посторонних запахов (гнилостного, плесени и др.)

Кисловато-сладкий, хлебный; без посторонних привкусов

$$
\begin{gathered}
46,6 \pm 0,1 \\
19,8 \pm 0,2 \\
3,4 \pm 0,1
\end{gathered}
$$

Не выявлено

Не выявлено

$-$

Tрава Agrimonia eupatoria l.

Смесь частиц цветков, листьев, стеблей; без пожелтевших, побуревших и почерневших частей растений;

без посторонних примесей

Венчиков - желтый; стеблей и листьев-зеленый

Сладко-абрикосовый; без посторонних запахов (гнилостного, плесени и др.)

Горьковатый; без посторонних привкусов

$$
8,4 \pm 0,1
$$

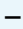

Не выявлено

$$
\begin{gathered}
9,20 \pm 0,01 \\
35,0 \pm 0,1
\end{gathered}
$$

\section{Технологическая схема нового вида кваса:}

- смешение квасного сусла с экстрактом из травы Agrimonia eupatoria L. и сахаром (с тем расчетом, чтобы начальная экстрактивность всех образцов поддерживалась на уровне 6,0 \%);

- сбраживание купажного сусла сухими хлебопекарными дрожжами при температуре $28-30{ }^{\circ} \mathrm{C}$ в течение 24 ч до снижения массовой доли сухих веществ на 2,0-2,5\%;

- охлаждение до $4-6{ }^{\circ} \mathrm{C}$ в течение 4 ч;

- осветление в течение 8 ч;

- розлив.

Стадия внесения в продукт экстракта из травы Agrimonia eupatoria L. определена по результатам предварительных испытаний с целью обеспечения напитку гармоничного флейвора. Если добавлять экстракт после сбраживания, то из-за недостаточной мацерации кваса будут присутствовать еле уловимые нотки вносимого компонента в аромате и вкусе.

Варианты образцов кваса, соотношение квасного сусла и экстракта из травы Agrimonia eupatoria L. :

- вариант № 1 - 90:10;

- вариант № 2-85:15;

- вариант № 3-80:20;
- вариант № 4 - 75:25;

- вариант № 5 - 70:30;

- контрольный - квасное сусло.

Методы исследования - стандартные, традиционно принятые в пивобезалкогольной отрасли:

- внешний вид и цвет кваса, травы Agrimonia eupatoria L., экстракта определяли визуально;

- запах и вкус кваса, травы Agrimonia eupatoria L., экстракта - органолептически;

- массовую долю влаги в квасе и траве Agrimonia eupatoria L. - высушиванием (до постоянной массы);

- массовую долю сухих веществ в экстракте, квасном сусле, квасе - рефрактометрическим методом;

- кислотность в экстракте, квасном сусле, квасе - титриметрическим методом;

- массовую долю металломагнитной примеси кваса - визуально, расчетным способом;

- наличие посторонних включений, хруста от минеральной примеси, признаков болезней и плесени, зараженности вредителями хлебных запасов кваса - визуально;

- содержание полифенольных веществ в траве Agrimonia eupatoria L., экстракте, квасном сусле, квасе - колориметрическим методом; 
- содержание аскорбиновой кислоты в траве Agrimonia eupatoria L., в экстракте, квасном сусле, квасе - титриметрическим методом;

- содержание этилового спирта в квасе - дистиляционным методом;

- органолептические показатели кваса - по балльной методике, разработанной Н.В. Заворохиной [14].

\section{Результаты исследования и их обсуждение}

Экстракт из травы Agrimonia eupatoria L. получали с учетом следующих факторов:

- в качестве растворителя использовали очищенную воду: она является хорошим растворителем большинства вкусоароматических соединений, полифенольных веществ, витаминов. Действующей нормативно-правовой документацией в квасе строго регламентируется содержание этилового спирта, а следовательно, использование последнего в качестве растворителя может привести к нарушению требований к продукту;

- температура мацерации - $40 \pm 3{ }^{\circ} \mathrm{C}$ (с точки зрения максимального выхода полифенольных и биологически активных веществ);

- измельчение травы - до частиц размером 3-5 мм;

- соотношение «сырье : растворитель» - 1:10;

- продолжительность мацерации (определена по содержанию растворимых сухих и полифенольных веществ, а также аскорбиновой кислоты (рис. 1-3) - не более 6 ч, поскольку после 5 ч мацерации по всем показателям не наблюдается выраженных изменений. Выбор контролируемых показателей обусловлен содержанием в траве Agrimonia eupatoria L. группы фенольных соединений, в которую входят флавоноиды (преимущественно изокверцетин и рутин), оксикоричные кислоты, процианиды и другие соединения, а также аскорбиновая кислота;

- фильтрация.

Качественные характеристики готового к использованию экстракта из травы Agrimonia eupatoria L. представлены в табл. 3.

Далее проведены исследования по определению оптимального количества вносимого экстракта Agrimonia eupatoria L. Физико-химические показатели образцов купажного сусла перед сбраживанием представлены в табл. 4. Как видно из таблицы, увеличение количества вносимого экстракта из травы Agrimonia eupatoria $L$. в квасное сусло приводит к незначительному снижению титруемой кислотности и значительному - содержания биологически активных веществ. Более заметно положительное влияние растительного экстракта на физико-химические показатели квасного сусла при его содержании свыше 20,0 \%.

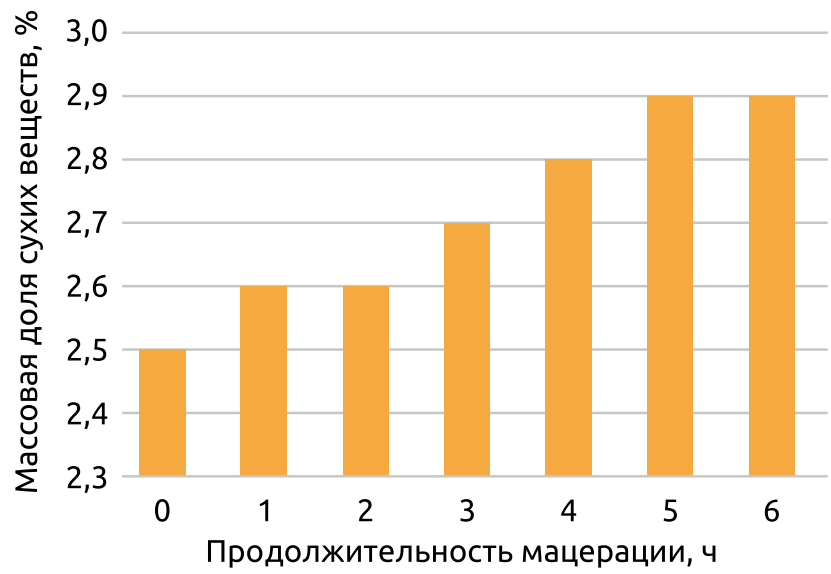

Рис. 1. Зависимость содержания сухих веществ от продолжительности мацерации

Fig. 1. Dependence of the Dry Matter Content on the Maceration Duration

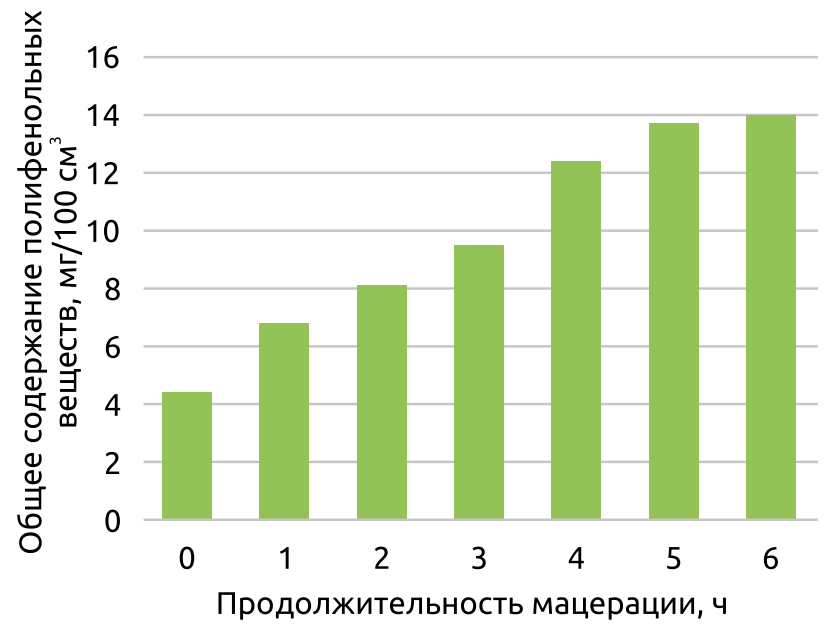

Puс. 2. Зависимость содержания полифенольных веществ от продолжительности мацерации, ч Fig. 2. Dependence of the Polyphenolic Substances Content on the Maceration Duration

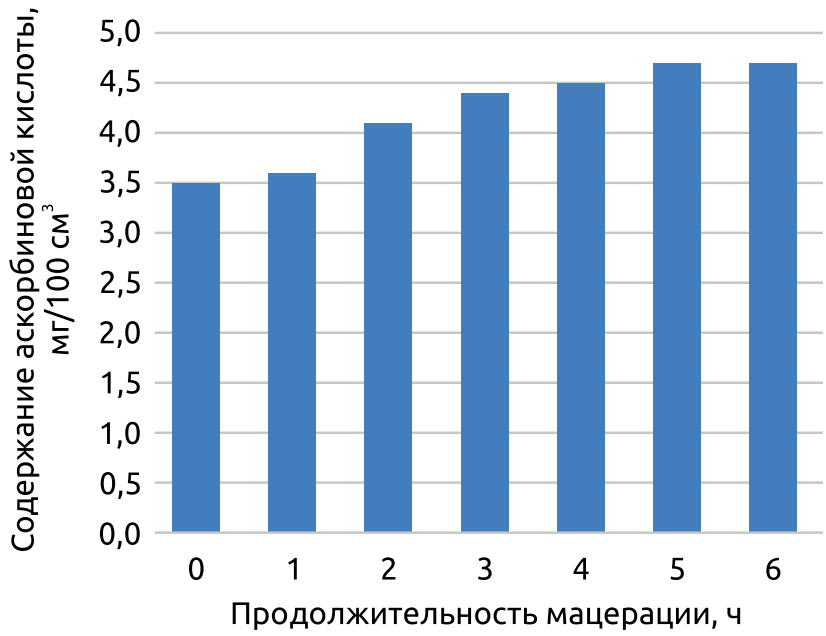

Рис. 1. Зависимость содержания аскорбиновой кислоты от продолжительности мацерации, ч

Fig. 1. Dependence of the Ascorbic Acid Content on the Maceration Duration 
Таблица 3. Качественные характеристики экстракта Agrimonia eupatoria L.

Table 3. Qualitative Characteristics of Agrimonia eupatoria L. Extract

\section{Показатель}

Внешний вид, прозрачность, цвет

Запах и вкус

Массовая доля сухих веществ, \%

Кислотность, к.ед.

Содержание полифенольных веществ, мг/100 см³

Содержание аскорбиновой кислоты, мг/100 см³

\section{Характеристика}

Непрозрачная коричневая жидкость со слабовыраженным зеленоватым оттенком

Слабовыраженные, сладко-абрикосовые, без посторонних оттенков

$$
\begin{aligned}
& 3,0 \pm 0,1 \\
& 2,5 \pm 0,2
\end{aligned}
$$

Не менее 13,5

Не менее 4,5

Таблица 4. Физико-химические показатели квасного сусла Table 4. Physical and Chemical Parameters of Kvass Wort

\begin{tabular}{|l|c|c|c|c|c|c|}
\multicolumn{1}{c|}{ Показатель } & \multicolumn{5}{c|}{ Образец } \\
\cline { 2 - 6 } & № 1 & № 2 & № 3 & № 4 & № 5 & Контрольный \\
\hline Массовая доля сухих веществ, \% & $6,0 \pm 0,1$ & $6,0 \pm 0,1$ & $6,0 \pm 0,1$ & $6,0 \pm 0,1$ & $6,0 \pm 0,1$ & $6,0 \pm 0,1$ \\
\hline Кислотность, к. ед. & $3,5 \pm 0,1$ & $3,4 \pm 0,1$ & $3,4 \pm 0,1$ & $3,2 \pm 0,1$ & $3,0 \pm 0,1$ & $3,6 \pm 0,1$ \\
\hline Содержание полифенольных веществ, мг/100 см³ & $1,8 \pm 0,1$ & $3,1 \pm 0,1$ & $5,7 \pm 0,1$ & $7,1 \pm 0,1$ & $9,0 \pm 0,1$ & $1,6 \pm 0,1$ \\
\hline Содержание аскорбиновой кислоты, мг/100 см33 & $1,5 \pm 0,1$ & $2,2 \pm 0,1$ & $2,7 \pm 0,1$ & $3,3 \pm 0,1$ & $3,9 \pm 0,1$ & $1,3 \pm 0,1$
\end{tabular}

Результаты органолептической оценки и физико-химические показатели исследуемых образцов кваса с экстрактом из травы Agrimonia eupatoria L. представлены на рис. 4 и в табл. 5.

Согласно органолептической оценке внесение экстракта Agrimonia eupatoria L. отразилось прежде всего на аромате / запахе и вкусе / послев- кусии кваса. Добавление экстракта на уровне 10,0-15,0 \% от общего объема практически не изменяет вышеуказанные характеристики напитка в сравнении с контрольным образцом. Добавление экстракта свыше 25,0 \% «утяжеляет» аналогичные характеристики, делая навязчивыми аромат / запах и вкус / послевкусие Agrimonia
Контрольный образец Образец № 5 Образец № 4 Образец № 3 Образец № 2 Образец № 1
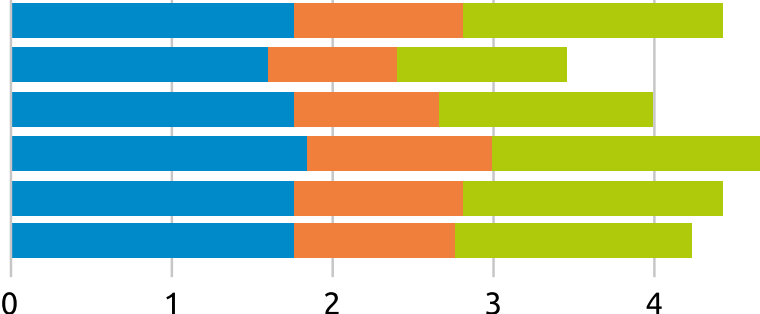

Рис. 4. Оченка органолептических показателей кваса

с добавлением экстракта из травы Agrimonia eupatoria L., балл

Fig. 4. Organoleptic Indicators Assessment of Kvass with Added Extract from the Herb Agrimonia eupatoria L., Score

Таблича 5. Физико-химические показатели кваса с добавлением экстракта из травы Agrimonia eupatoria L.

\begin{tabular}{|c|c|c|c|c|c|c|}
\hline \multirow{2}{*}{ Показатель } & \multicolumn{6}{|c|}{ Образец } \\
\hline & № 1 & № 2 & № 3 & № 4 & № 5 & Контрольный \\
\hline Массовая доля сухих веществ, \% & $3,8 \pm 0,1$ & $3,8 \pm 0,1$ & $4,0 \pm 0,1$ & $4,2 \pm 0,1$ & $4,4 \pm 0,1$ & $3,8 \pm 0,1$ \\
\hline Кислотность, к.ед. & $4,1 \pm 0,1$ & $4,0 \pm 0,1$ & $3,8 \pm 0,1$ & $3,7 \pm 0,1$ & $3,5 \pm 0,1$ & $4,2 \pm 0,1$ \\
\hline Объемная доля спирта, \% & $1,1 \pm 0,1$ & $1,1 \pm 0,1$ & $0,9 \pm 0,1$ & $0,9 \pm 0,1$ & $0,8 \pm 0,1$ & $1,1 \pm 0,1$ \\
\hline Содержание полифенольных веществ, мг/100 см³ & $1,6 \pm 0,1$ & $3,0 \pm 0,1$ & $5,1 \pm 0,1$ & $6,7 \pm 0,1$ & $8,5 \pm 0,1$ & $1,4 \pm 0,1$ \\
\hline $\begin{array}{l}\text { Содержание аскорбиновой кислоты, мг/мг/100 } \\
\text { см³ }^{3}\end{array}$ & $1,4 \pm 0,1$ & $2,1 \pm 0,1$ & $2,5 \pm 0,1$ & $3,1 \pm 0,1$ & $3,6 \pm 0,1$ & $1,2 \pm 0,1$ \\
\hline
\end{tabular}
Table 5. Physical and Chemical Parameters of Kvass with Added Extract from the Herb Agrimonia eupatoria L. 
eupatoria L. Напитки независимо от содержания экстракта по внешнему виду, в том числе по цвету, различались незначительно. По мере увеличения количества вводимого экстракта снижаются показатели интенсивности выделения пузырьков углекислого газа и стойкости пены.

Как видно из табл. 5, внесение экстракта Agrimonia eupatoria $L$. в квас заметно изменяет его физико-химические показатели, причем с увеличением количества вносимого растительного полуфабриката эти изменения более выражены. Так, увеличение содержания экстракта Agrimonia eupatoria L. в квасе приводит к получению напитка с бо́льшим количеством сухих веществ, что является следствием менее интенсивного брожения квасного сусла. Последнее сказывается на накоплении этилового спирта в готовом напитке - увеличение доли экстракта способствует меньшему накоплению данного соединения. Кислотность напитков выражается более низким показателем при добавлении экстракта в большем объеме, что отражается на вкусе - он становится более мягким, менее резким.

\section{Библиографический список}

1. Бабий Н.В., Помозова В.И., Песков Д.Б. Особенности проектирования тонизирующих напитков для повышения резистентности организма // Техника и технология пищевых производств. 2016. № 2 (41). C. 13-20.

2. Потороко И.Ю., Калинина И.В., Фаткуллин Р.И., Иванова Д., Ки селова-Канева Й.Д. Результаты влияния кавитационных эффектов ультразвука на степень экстракции биологически активных веществ из растительного сырья // Аграрный вестник Урала. 2017. № 10 (164). С. 30-35.

3. Каухова И.Е., Новикова Е.К., Чачин Д.А. Разработка условий экстрагирования череды трехраздельной травы, золотарника канадского травы, репешка обыкновенного травы // Разработка и регистрация лекарственных средств. 2018. № 3 (24). С. 64-67.

4. Зуева А.А., Веденеев А.М. Лекарственные растения Еланского района Волгоградской области // Актуальные вопросы теории и практики биологического и химического образования: материалы XIII Всерос. с междунар. участием науч. - практ. конф. (Волгоград, 1-30 апреля 2019 г.). Волгоград: Планета, 2019. С. 106-109.

5. Курманова Е.Н., Стрелкова Л.Б., Ферубко Е.В., Шейченко О.П. Гепатозащитное действие экстракта репешка обыкновенного при экспериментальном тетрахлорметановом гепатите // Вопросы биологической, медицинской и фармацевтической химии. 2020. Т. 23, № 2. С. 37-41. DOI: 10.29296/25877313-2020-02-06.

6. Cardoso, 0.; Donato, M.M.; Luxo, C.; Nuno Almeida; Joana Liberal; Artur Figueirinha; Maria Teresa Batista. Anti-Helicobacter Pylori Potential of Agrimonia Eupatoria L. and Fragaria Vesca. Journal of Functional Foods. 2018. Vol. 44. Pp. 299-303. DOI: 10.1016/j. jff.2018.03.027.
Установлено, что даже небольшое содержание экстракта в напитке способствует большему выходу полифенольных соединений и аскорбиновой кислоты в сравнении с контрольным образцом. При этом чем больше доля экстракта, тем выше содержание биологически активных веществ.

\section{Выводы}

Проведенные исследования подтвердили возможность использования водного экстракта травы Agrimonia eupatoria L. в производстве кваса. Экстракт предпочтительнее вносить в квасное сусло в количестве, не превышающем 20,0 \% последнего. Получаемый напиток отличается оригинальными органолептическими характеристиками и повышенным содержанием биологически активных веществ.

Данные технологии и рецептура приготовления кваса с использованием экстракта травы Agrimonia eupatoria L. могут быть рекомендованы для расширения ассортимента безалкогольных напитков.

\section{Bibliography}

1. Babii, N.V.; Pomozova, V.I.; Peskov, D.B. Osobennosti Proektirovaniya Toniziruyushchih Napitkov dlya Povysheniya Rezistentnosti Organizma [Project Features of Tonic Drinks to Increase the Body's Resistance]. Tekhnika i Tekhnologiya Pishchevyh Proizvodstv. 2016. No 2 (41). Pp. 13-20.

2. Potoroko, I.Yu.; Kalinina, I.V.; Fatkullin, R.I.; Ivanova, D.; Kiselova-Kaneva, I.D. Rezul'taty Vliyaniya Kavitacionnyh Effektov Ul'trazvuka na Stepen' Ekstrakcii Biologicheski Aktivnyh Veshchestv iz Rastitel'nogo Syr'ya [Influence Results of Cavitation Ultrasound Effects on the Extraction Degree of Biologically Active Additives from Plant Raw Materials]. Agrarnyj Vestnik Urala. 2017. № 10 (164). Pp. 30-35.

3. Kauhova, I.E.; Novikova, E.K.; Chashchin, D.A. Razrabotka Uslovii Ekstragirovaniya Cheredy Trekhrazdel'noi Travy, Zolotarnika Kanadskogo Travy, Repeshka Obyknovennogo Travy [Conditions Development for Extracting a Bur Beggare Grass, Canadian Goldenrod Grass, Common Agrimony Grass]. Razrabotka i Registraciya Lekarstvennyh Sredstv. 2018. No 3 (24). Pp. 64-67.

4. Zueva, A.A.; Vedeneev, A.M. Lekarstvennye Rasteniya Elanskogo Raiona Volgogradskoi Oblasti [Medicinal Plants of the Elansky Area of the Volgograd Region]. Aktual'nye Voprosy Teorii i Praktiki Biologicheskogo i Himicheskogo Obrazovaniya: Materialy XIII Vseros. S Mezhdunar. Uchastiem Nauch. - Prakt. Konf. (Volgograd, 1-30 aprelya 2019 g.). Volgograd: Planeta, 2019. Pp. 106-109.

5. Kurmanova, E.N.; Strelkova, L.B.; Ferubko, E.V.; Sheichenko, O.P. Gepatozashchitnoe Dejstvie Ekstrakta Repeshka Obyknovennogo pri Eksperimental'nom Tetrahlormetanovom Gepatite [Hepatoprotective Effect of Common Agrimony Extract in Experimental Tetrachloromethane Hepatitis]. Voprosy Biologicheskoi, Medicinskoi i Farmacevticheskoi Himii. 2020. T. 23, No 2. S. 37-41. DOI: 10.29296/25877313-2020-02-06. 
7. Granica, G.; Kluge, H.; Horn, G.; Matkowski, A.; Kiss, A.K. The Phytochemical Investigation of Agrimonia Eupatoria L. and Agrimonia Procera Wallr. as Valid Sources of Agrimoniae Herba - The Pharmacopoeial Plant Material. Journal of Pharmaceutical and Biomedical Analysis. 2015. Vol. 114. Pp. 272-279. DOI: 10.1016/j. jpba.2015.05.027.

8. Хадарцев А.А., Платонов В.В., Сухих Г.Т.,, Дунаев Г.Т., Мелякова Д.А. Химический состав органического вещества травы репешка обыкновенного (приворот обыкновенный) (Argimonia eupatoria L., семейство розоцветных - Rosaceae) // Вестник новых медицинских технологий. 2018. Т. 25, № 4. С. 127-136.

9. Ginovyan, M.; Ayvazyan, A.; Nikoyan, A.; Tumanyan, L.; Trchounian, A. Phytochemical Screening and Detection of Antibacterial Components from Crude Extracts of Some Armenian Herbs Using TLC-Bioautographic Technique. Current Microbiology. 2020. 77(7). Pp. 1223-1232. DOI: 10.1007/s00284-020-01929-0.

10. Muruzović, M.Ž.; Mladenović, K.G.; Stefanović, O.D., et al. (Sava M. Vasić, Ljiljana R. Čomić ) Extracts of Agrimonia Eupatoria L. as Sources of Biologically Active Compounds and Evaluation of Their Antioxidant, Antimicrobial, and Antibiofilm Activities. Journal of Food and Drug Analysis. 2016. Vol. 24, iss. 3. Pp. 539-547. DOI: 10.1016/j.jfda.2016.02.007.

11. Santos, T.N.; Costa, G.; Ferreira, J.P., et al. Antioxidant, Anti- Inflammatory, and Analgesic Activities of Agrimonia Eupatoria L. Infusion. Evidence-Based Complementary and Alternative Medicine. 2017. Article ID: 8309894. DOI: 10.1155/2017/8309894.

12. 12.Tsirigotis-Maniecka, M.; Pawlaczyk-Graja, I.; Ziewiecki, R., et al. The Polyphenolic-Polysaccharide Complex of Agrimonia Eupatoria L. as an Indirect Thrombin Inhibitor - Isolation and Chemical Characterization. International Journal of Biological Macromolecules. 2019. Vol. 125. Pp. 124-132. DOI: 10.1016/j. ijbiomac.2018.12.017.

13. Голу6 О.В., Миллер Ю.Ю., Захарова К.В. Использование репешка обыкновенного в пищевой промышленности // Пища. Экология. Качество: с6. тр. XV Междунар. науч.-практ. конф. (Новосибирск, 27-29 июня 2018 г.): в 2 т. Новосибирск: Изд. центр «Золотой ко лос", 2018. С. 144-149.

14. Заворохина Н.В. Разработка и применение методологии моделирования безалкогольных напитков с учетом сенсорных предпочтений потребителей: дис. ... д-ра техн. наук: 05.18.15. Кемерово, 2014. 319 c.
6. Cardoso, 0.; Donato, M.M.; Luxo, C.; Nuno Almeida; Joana Liberal; Artur Figueirinha; Maria Teresa Batista. Anti-Helicobacter Pylori Potential of Agrimonia Eupatoria L. and Fragaria Vesca. Journal of Functional Foods. 2018. Vol. 44. Pp. 299-303. DOI: 10.1016/j. jff.2018.03.027.

7. Granica, G.; Kluge, H.; Horn, G.; Matkowski, A.; Kiss, A.K. The Phytochemical Investigation of Agrimonia Eupatoria L. and Agrimonia Procera Wallr. as Valid Sources of Agrimoniae Herba - The Pharmacopoeial Plant Material. Journal of Pharmaceutical and Biomedical Analysis. 2015. Vol. 114. Pp. 272-279. DOI: 10.1016/j. jpba.2015.05.027.

8. Hadarcev, A.A.; Platonov, V.V.; Suhih, G.T.; Dunaev, G.T.; Melyakova, D.A. Himicheskij Sostav Organicheskogo Veshchestva Travy Repeshka Obyknovennogo (Privorot Obyknovennyj) (Argimonia Eupatoria L., Semejstvo Rozocvetnyh - Rosaceae) [Chemical Composition of the Organic Substance of the Common Agrimony Grass (Argimonia Eupatoria L., Rosaceae Family)]. Vestnik Novyh Medicinskih Tekhnologii. 2018. T. 25, No 4. Pp. 127-136.

9. Ginovyan, M.; Ayvazyan, A.; Nikoyan, A.; Tumanyan, L.; Trchounian, A. Phytochemical Screening and Detection of Antibacterial Components from Crude Extracts of Some Armenian Herbs Using TLC-Bioautographic Technique. Current Microbiology. 2020. 77(7). Pp. 1223-1232. DOI: 10.1007/s00284-020-01929-0.

10. Muruzović, M.Ž.; Mladenović, K.G.; Stefanović, O.D., et al. (Sava M. Vasić, Ljiljana R. Čomić ) Extracts of Agrimonia Eupatoria L. as Sources of Biologically Active Compounds and Evaluation of Their Antioxidant, Antimicrobial, and Antibiofilm Activities. Journal of Food and Drug Analysis. 2016. Vol. 24, iss. 3. Pp. 539-547. D0l: 10.1016/j.jfda.2016.02.007.

11. Santos, T.N.; Costa, G.; Ferreira, J.P., et al. Antioxidant, Anti- Inflammatory, and Analgesic Activities of Agrimonia Eupatoria L. Infusion. Evidence-Based Complementary and Alternative Medicine. 2017. Article ID: 8309894. DOI: 10.1155/2017/8309894.

12. 12.Tsirigotis-Maniecka, M.; Pawlaczyk-Graja, I.; Ziewiecki, R., et al. The Polyphenolic-Polysaccharide Complex of Agrimonia Eupatoria L. as an Indirect Thrombin Inhibitor - Isolation and Chemical Characterization. International Journal of Biological Macromolecules. 2019. Vol. 125. Pp. 124-132. DOI: 10.1016/j. ijbiomac.2018.12.017.

13. Golub O.V., Miller YU.YU., Zaharova K.V. Ispol'zovanie Repeshka Obyknovennogo v Pishchevoj Promyshlennosti [Use of Common Agrimony in the Food Industry]. Pishcha. Ekologiya. Kachestvo: sb. tr. XV Mezhdunar. Nauch.-Prakt. Konf. (Novosibirsk, 27-29 Iyunya 2018 g.): v 2 t. Novosibirsk: Izd. Centr «Zolotoi Kolos», 2018. Pp. 144-149.

14. Zavorohina N.V. Razrabotka i Primenenie Metodologii Modelirovaniya Bezalkogol'nyh Napitkov s Uchetom Sensornyh Predpochtenii Potrebitelej [Development and Application of Methodology for Modeling Soft Drinks Considering the Sensory Preferences of consumers]: dis. ... d-ra tekhn. nauk: 05.18.15. Kemerovo, 2014. $319 \mathrm{p}$.

\section{Информация 06 авторах / Information about Authors}

\section{Миллер Юлия Юрьевна}

Miller, Yuliya Yurievna

Тел./Phone: +7 (383) 346-17-53 E-mail:expertis@sibupk.nsk.su
Кандидат технических наук, дочент кафедры товароведения и экспертизы товаров Сибирский университет потребительской кооперации 630087, Российская Федерация, г. Новосибирск, пр. Карла Маркса, 26

Candidate of Technical Sciences, Associate Professor of the Commodity and Goods Examination Department

Siberian University of Consumer Cooperation

630087, Russian Federation, Novosibirsk, Karl Marks Ave., 26

ORCID: https://orcid.org/0000-0001-5490-4804 


\section{Голуб}

\section{Ольга Валентиновна}

Golub,

Olga Valentinovna

тел./Phone: +7 (383) 346-17-53

E-mail:expertis@sibupk.nsk.su

\section{Захарова}

Карина Владимировна

Zakharova,

Karina Vladimirovna

тел./Phone: +7 (383) 346-17-53

E-mail:expertis@sibupk.nsk.su
Доктор технических наук, профессор, профессор кафедры товароведения

и экспертизы товаров

Сибирский университет потребительской кооперации

630087, Российская Федерация, г. Новосибирск, пр. Карла Маркса, 26

Doctor of Technical Sciences, Professor, Professor of the Commodity and Goods Examination Department

Siberian University of Consumer Cooperation

630087, Russian Federation, Novosibirsk, Karl Marks Ave., 26

ORCID: https://orcid.org/0000-0003-2561-9953

\section{Студент}

Сибирский университет потребительской кооперации

630087, Российская Федерация, г. Новосибирск, пр. Карла Маркса, 26

Student

Siberian University of Consumer Cooperation

630087, Russian Federation, Novosibirsk, Karl Marks Ave., 26

ORCID: https://orcid.org/0000-0003-3111-218X 